\title{
Influência da centrifugação na agregação plaquetária durante processamento do plasma rico em plaquetas e sua relação com a concentração de TGF-beta final
}

Sarah Raphaela Torquato Seide ${ }^{[a]^{*}}$, Cynthia do Prado Vendrusculo ${ }^{[a]}$, Fernanda Rodrigues Agreste ${ }^{[a]}$, Joice Fülber ${ }^{[a]}$, Juliana Junqueira Moreira ${ }^{[a]}$, Yara Maria Michelaccib] ${ }^{[b]}$ Raquel Yvonne Arantes Baccarin ${ }^{[a]}$

\footnotetext{
[a] Faculdade de Medicina Veterinária e Zootecnia, Universidade de São Paulo (USP), São Paulo, SP, Brasil

${ }^{[b]}$ Escola Paulista de Medicina, Universidade Federal de São Paulo (UNIFESP), São Paulo, SP, Brasil
}

*Autor correspondente

e-mail: sarahseidel@usp.br

\section{Resumo}

O Plasma Rico em Plaquetas (PRP) é um produto autólogo, hemoderivado, de fácil aquisição e baixo custo, apresentando em sua composição plaquetas, fatores de crescimento, proteínas plasmáticas, algumas hemácias e leucócitos; e tem se mostrado de ampla aplicabilidade no tratamento das afecções locomotoras em equinos, com resultados satisfatórios em uso intra-articular, intralesional em tendinites e no tratamento adjunto de laminite crônica. Objetivou-se avaliar o grau de ativação das plaquetas provocado pelas centrifugações durante o processamento do PRP, bem como o impacto desta ativação na concentração plaquetária obtida e sua correlação com a concentração de TGF $\beta 1$ final. Foram utilizados 12 equinos, Árabes, machos, de 3 a 5 anos, clinicamente sadios, sendo realizados dois protocolos de PRP, um com centrifugação única e outro com dupla centrifugação. No primeiro, foram coletados $10 \mathrm{ml}$ de sangue total de cada animal por meio de punção da veia jugular externa, com uso de agulha $21 \mathrm{G}$ e seringa de $10 \mathrm{ml}$, sendo esse volume imediatamente transferido para tubos falcon contendo citrato de sódio a 3,8\% na proporção 1:10, homogeneizado e centrifugado a 141g/12 minutos, à To ambiente, e seu sobrenadante denominado PRP0. Para o segundo, o sangue foi coletado com vacutainer em tubos com capacidade de 4,5ml contendo citrato de sódio a 3,8\%, totalizando $20 \mathrm{ml}$ de sangue total por animal. Após homogeneização, as amostras foram transferidas para 3 tubos falcon, permanecendo em repouso à To ambiente por 25 minutos, centrifugadas a $300 \mathrm{~g} / 5$ minutos, seguido de novo repouso de 25 minutos. 0 sobrenadante do tubo 1 foi denominado plasma pobre em plaquetas 1 (PPP1). 0 sobrenadante dos tubos restantes foi transferido a dois novos tubos falcon, procedendo a nova centrifugação de $700 \mathrm{~g} / 15$ minutos, com 45 minutos de repouso à To ambiente. Em seguida, o sobrenadante do tubo 2 em sua porção mais superior foi denominado PPP2, enquanto 70\% do sobrenadante do tubo 3 foi descartado e sua porção remanescente homogeneizada e classificada como PRP1. 
As amostras, previamente identificadas, foram submetidas à contagem plaquetária manual em câmara de Neubauer e à avaliação da agregação plaquetária em aparelho agregômetro Chrono-Log Corporation, pelo método turbidimétrico, com uso do agonista colágeno tipo 1 na proporção $2 \mu \mathrm{l}$ agonista:500 $\mu \mathrm{l}$ amostra para induzir a mesma. Após avaliação, foram armazenadas a $-80^{\circ} \mathrm{C}$, sendo o fator de crescimento posteriormente quantificado por meio de kit ELISA Human TGFß1 Quantikine, validado para a espécie equina. As maiores contagens plaquetárias alcançadas foram no PRP1 (duas centrifugações), concentrando em média 6,8x, e as demais frações com média de 4,1x para o PPP1, 2,6x no PRP0 e, por fim, o PPP2 com 0,33x. 0 PPP2 não foi submetido ao teste de agregação plaquetária. A média apresentada pelos demais foi: 100\% para o PRP0, 90\% para o PPP1 e 66,8\% para o PRP1. A quantificação do TGFß1 obtida foi: 5.537,3 pg/ $\mu$ para PRP0,

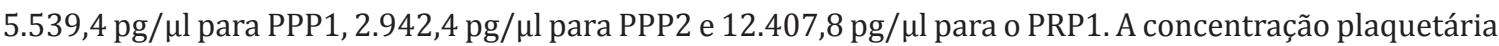
alcançada no PPP1 e PRP1 é condizente com a necessária para classificar o produto como PRP, ou seja, no mínimo $4 \mathrm{x}$ acima da basal. A quantidade de TGFß1 apresentou aumento à medida em que as concentrações plaquetárias aumentaram, evidenciando correlação positiva entre as mesmas. É possível observar que no mínimo 30\% do PRP1 já havia sido ativado durante a centrifugação, o que pode explicar a quantidade de TGFß1 encontrada no PPP2, que possuiu a menor contagem plaquetária, bem como a semelhança de valores de TGFß1 demonstrada nas amostras de PRP0 e PPP1. Conclui-se que a dupla centrifugação com o intuito de obter maior concentração plaquetária é vantajosa em relação à centrifugação única, mesmo produzindo maior agregação plaquetária durante o processamento do PRP. Isto porque quanto maior a concentração plaquetária atingida, maior a concentração de TGFß1 disponível.

Palavras-chave: Plasma rico em plaquetas. Fator de crescimento. Agregação plaquetária.

Agradecimentos: à CAPES pela concessão de bolsa de estudo. 